\title{
The Impact of Cloud Computing on Decision Support System in Adopting Knowledge Management in Saudi Organizations
}

\author{
Bader A. Alyoubi*, Adel A. Alyoubi, Haneen H. Alahmadi and Najah K. Almazmomi \\ Department of Management Information Systems, College of Business, University of Jeddah, Saudi Arabia; \\ balyoubi@uj.edu.sa,balyoubi@uj.edu.sa,hhalahamade@uj.edu.sa,nalmazmomi@uj.edu.sa
}

\begin{abstract}
Background/Objectives: Due to enormous increase in the volume of the information within and outside of the organizations, traditional business and information models are unable to cater to the needs of the modern business needs. Methods/Findings: In this context, Cloud Computing (CC) is gaining rapid popularity amongst businesses due to its ability to handle technical and organisational facets. Cloud Computing has evolved as a reliable technology, offering enhanced Decision Support Systems (DSS) at a low cost for the organizations. CC has displayed its capability of handling large volumes of data and providing seamless services to the companies. This research explored the impact of CC on DSS and Knowledge Management (KM) on Saudi organizations. The major achievement of this research was to fill the gap in knowledge by researching the impact of integration of CC, DSS and KM for Saudi organizations. The key finding of this research is that there is a significant positive impact of CC on DSS and KM in Saudi organizations. Based on this extensive research, we strongly believe that by taking recommended precautionary measures, security concerns about CC could be overcome resulting in benefits outweighing the risks for Saudi organizations. Application: Based on the literature and qualitative research, we recommend that Saudi organizations should consider migrating from traditional business models to Cloud Computing to stay competitive in this globalised world.
\end{abstract}

Keywords: Cloud Computing, Decision Support Systems, Knowledge Management

\section{Introduction}

Cloud Computing (CC) technology has gained enormous popularity in the modern business world. CC has grown to an extent that no organisation can afford to ignore anymore. The advancement in the technology has enabled the management to enhance their decision-making ability by making use of the latest technologies resulting in greater organisational efficiency $\frac{1}{}$. Rightly argued that the reason behind the success of CC has to be attributed to the ability to deal with both technical and organisational facets. Decision Support Systems (DSS) came into existence to make the transformation from subjective to objective sustainable through data accumulation, realisation and distribution. Knowledge Management (KM) plays a critical role in the organisation's success ${ }^{2}$. We firmly concur with the views of ${ }^{3}$, who stated that information is the crucial element in this data-driven business world.

$\operatorname{In}^{4}$ reported that many organizations are slow in adopting new technologies for various reasons such as sceptical cost-benefit ratio, staff training, reluctance to change and many more. This view was substantiated by a detailed research conducted by $y^{\underline{5}}$ on Saudi organizations. The authors reported that majority of the Saudi companies are slow in adopting the latest technologies. The popular reasons they reported were lack of technical knowledge, huge range of latest technologies in the market, past experience and ambiguity about impact

${ }^{*}$ Author for correspondence 
of new technology on the organisation's objectives. We share the views of ${ }^{6}$ who believe that researchers have the ability to address the concerns of business community and help them make right decisions. There is a lack of research about the impact of CC that is specific to Saudi organizations. Therefore, we have undertaken this research to help the business community in Saudi Arabia that are set to take a leap into the new era of information. This research critically evaluates the impact of CC on DSS, KM and strategic objectives of Saudi organizations along with cost-benefit analysis. This research takes a two-step approach: 1. Establish the impact of CC on DSS and KM using literature research and 2. Gather primary data to validate the theoretical findings through qualitative research method by conducting interviews with the professionals having enormous knowledge and experience in the field of management and technology currently working for Saudi organizations.

\section{Decision Support System (DSS)}

DSS, as the name suggests, is a concept that makes use of available information to help user analyse the situation and make better decisions. DSS defined as interactive software-based tool aimed at enhancing the user's ability to make decisions. DSS are mainly used by mid-level and high-level management staff in an organisation ${ }^{\text {? }}$. The problems are identified, making use of the raw data, knowledge, models and communications technology. Figure 1 illustrates the DSS models that includes, 1. Behaviour models, 2. Management models and 3. Operational Research (OR) models.

Behaviour models help users understand the behaviour of various business variables. Some of the examples include sales forecast, trend analysis and other statistical models. Management science models are based on the management accounting and economics. Some of the examples are cost accounting, budgeting and return on investment systems. OR model is a mathematical-based approach that uses variables and constants to represent the real-world problems ${ }^{8}$. The key objective is to identify an optimum solution that maximises certain parameters in a given condition and constraints.

The three main components of DSS consist of database, model base and user interface. The database holds both internal and external data that the DSS model can make use of to cater to the analysis needs of the user. Figure 2 depicts the key components of DSS model.
The intention of understanding the various models is to realise the complexity and the amount of data that the management has to deal with every day in making decisions. We strongly believe that DSS plays a pivotal role in helping them analyse the data of this nature efficiently and enables them to make effective decisions.

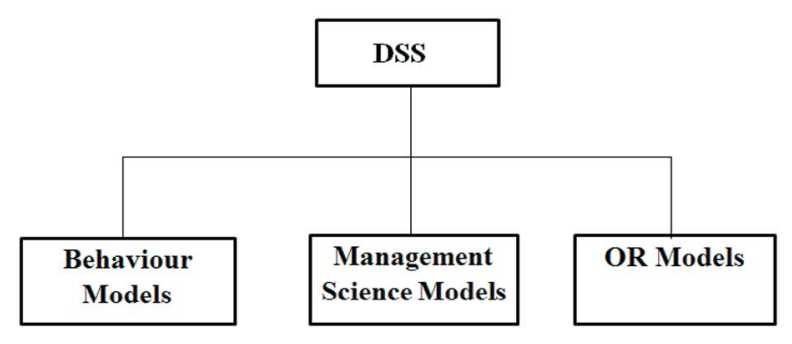

Figure 1. DSS models ${ }^{\mathrm{T}}$.

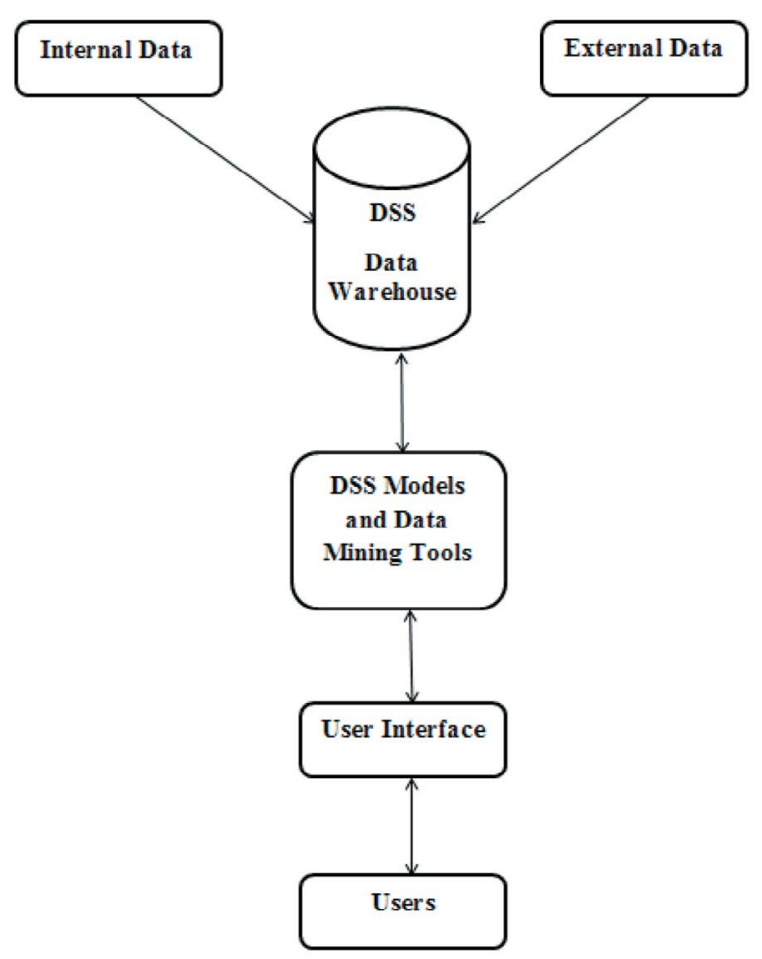

Figure 2. Key components of DSS.

\section{Knowledge Management (KM)}

Knowledge defined as the individual's ability to resolve complex problems through abstracting, comprehending, speculating and acting on issue at hand? ${ }^{2}$. This feature of knowledge makes it subjective in nature and varies from person to person whilst dealing with similar situations. 
However, organizations are adopting KM models to make less subjective and make use of it in future by developing KM models. This would give them the edge to statistically identify strategies that worked for them previously that are similar to current situations. KM holds all the relevant information of each and every situation that the decision makers had to take. KM follows a simple procedure of defining, capturing, manipulating, storing, and developing information systems for knowledge creation. Figure 3 shows the architecture of KM systems.

$\mathrm{In}^{10}$ rightly argued that with the rapidly increasing Internet popularity and the emergence of social media has drastically changed the dimension of business models. We believe that the organizations that are capable of managing data efficiently will be rewarded with an edge over its competitors. In this context, it is also clear that traditional data handling tools and methods are not able to handle such large volumes of information. This view is substantiated by the emergence and rising popularity of Big Data and Cloud Computing technologies that specifically deals with large volumes of data efficiently.

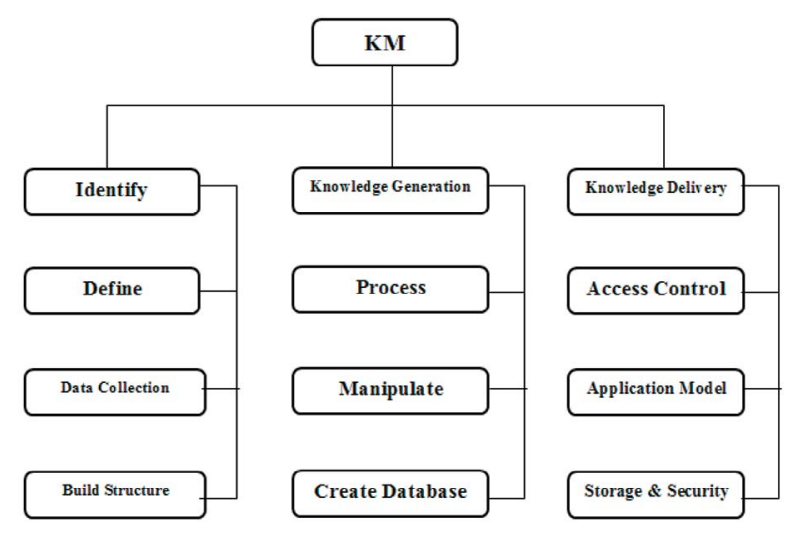

Figure 3. KM architecture.

\section{Cloud Computing (CC)}

CC defined as a sophisticated strategic platform offering highly reliable data centre architecture that combines several technologies and business models like virtualisation, distributed computing and pay-per-use models ${ }^{4}$. It is growing at an exponential rate and it has been reported that CC is will hit $\$ 240$ billion by $2020^{9}$. However, many organizations in Saudi Arabia and many other countries are yet to upgrade from traditional DSS to CC integrated DSS. The services offered by CC are shown in Figure 4.
CC offers four deployment models for organizations: Hybrid, public, private and community cloud. CC offers three service models: Software as a Service (SaaS), Platform as a Service (PaaS) and Infrastructure as a Service (IaaS). The key salient features of CC are on-demand self-service, resource pooling, broad network access, cost-effective storage, measured service and a secured network. This research primarily focuses on the impact of implementing CC for DSS in KM. It becomes necessary to understand the relationship between each of them to evaluate the impact of CC on organizations.

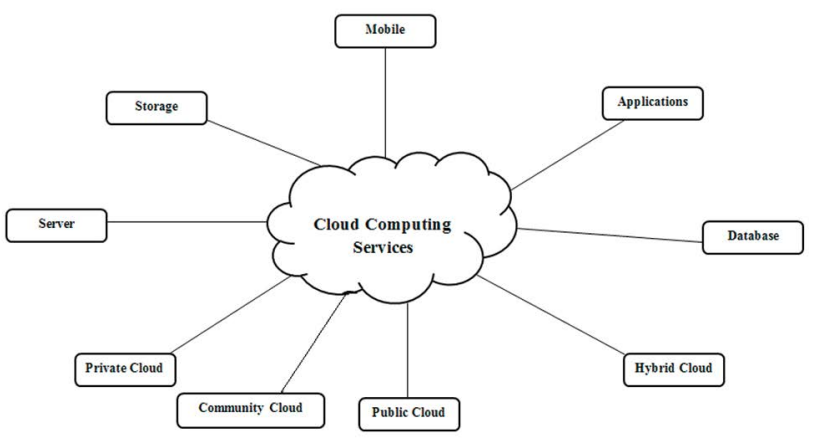

Figure 4. Cloud Computing services.

\section{Relationship between DSS and $\mathrm{KM}$}

DSS is mainly used by mid-level and high-level management staff in an organisation. As explained earlier, DSS is about providing the user-requested data for analysis from its databases that will aid the user to make better decisions. It's pointed out that knowledge within the organisation has to be managed so that the knowledge available can be accessed by anyone anytime ${ }^{11}$. This information is highly valuable as most of it could be obtained by experience and can have a huge impact whilst dealing with issues within the organisation. The $\mathrm{KM}$ framework is comprised of creating new business knowledge, storing it, making it accessible throughout the company. There are two kinds of knowledge: Explicit and tacit knowledge. Explicit knowledge is about documents, data stored in computers, paper documents, etc. Tacit knowledge is about enormous knowledge that is, in the employees' minds, represents some critical information within the organisation. We share the views of $\frac{12}{2}$ that explicit knowledge is easy to manage and tacit knowledge is relatively complex and difficult to manage but it is of high value to the organisation. Integrating DSS with KM 
facilitates capturing, storing and making information available throughout the organisation. KM is one of the sources of information for DSS and a vital one for the organisation.

\section{Relationship between Cloud Computing and DSS}

It has been established that huge amount of information flows within the organisation. To handle such large amounts of data, a robust framework that is up-to-date with the latest technologies is of prime importance. Traditional business models and infrastructure is not capable of handling the current complex data. The decision-making has evolved over the years significantly and with the emergence of DSS, it has seen a major shift in decision-making, enabling the management to take decisions quickly and consistently ${ }^{5}$. CC enhances the capability of DSS at much lower costs without compromising on software, platform and infrastructure quality. Organizations can opt for services according to their requirements by starting with pay-per-use and upgrade services as and when required. Migrating to CC services costs less compared to upgrading the organisation's existing traditional business models and framework. Therefore, it can be concluded that CC has the potential to act as a driving force for DSS in this information era.

\section{Relationship between Cloud Computing and KM}

The success of CC has to be attributed to the availability of high-speed internet, reduction in storage costs and emergence of Smart phones with high processing and internet speed around the world. This has impacted the way $\mathrm{KM}$ is handled within the organisation. It is surprising to see if a user is not aware of search engines that open the door to the wealth of information. However, incorrect information is also on the high in the public domain. This becomes a challenge for companies to protect its customers, vendors, employees, etc., from inaccurate information $\frac{13}{}$. It is a well-known fact that transmission of corporate knowledge is slow and rarely meets the needs of the user. Therefore, it is critical that companies build $\mathrm{KM}$ framework with the ability to respond to the user's needs effectively with minimum turnaround time. CC is the answer to this challenge faced by the organizations. Cloud storage models can be used to accomplish the complex data storage requirements for maintaining $\mathrm{KM}$ systems.CC offers the companies to frame highly scalable and reliable weboriented architecture to achieve well-connected and collaborative $\mathrm{KM}$ systems ${ }^{14}$.

\section{Current Challenges of DSS in adopting KM}

We noticed that the two major issues organizations face whilst integrating DSS with KM is the streamlining of tacit knowledge and handling of large amounts of data emanating from KM. Because of these two challenges, organizations fail to make full use of KM. The rise in social media has its own benefits and drawbacks for organizations due to high amount of inaccurate data that can reach the user ahead of accurate data that has been released by corporate ${ }^{6}$. With the traditional information architecture, it becomes unrealistic for organizations to dissipate information quickly as explained earlier. Because of the restrictions of volume handling capacity of DSS, some of the valuable information in the KM systems gets left out and impacts the quality of decision-making by the management. We strongly support the view of $\frac{15}{}$, who reported that investment in tacit knowledge is considered as overheads by the management due to high costs and difficulty in streamlining the information gathering, storing and dissipating. This situation perfectly presents an opportunity for CC to put forward a strong business case for its implementation, by offering enhanced software, infrastructure and platform services at a low cost that can manage high volumes of data emanating from all sources of organisation both internal and external. Therefore, it is concluded from literature research that $\mathrm{CC}$ has a huge positive impact on both DSS and KM. Qualitative research has been carried by conducting interviews to validate the theoretical findings.

\section{Research Problem}

Based on the literature research, it is evident that CC has a positive impact on DSS and KM. Validating the theoretical findings is necessary to bring credibility, adaptability and add quality to the research work ${ }^{16}$. Saudi organizations are slow in adopting new technologies and 
it becomes relevant for this research to understand the reasons for this trend ${ }^{5}$. To achieve this, interviews were conducted with highly experienced professionals in Saudi Arabia.

\section{Research Method}

Due to the complex nature of the research topic and the need for exploring hidden truths, qualitative research approach has been used for this research. As this research is about Saudi organizations, the participants for interviews selected are professionals working for organizations in Saudi Arabia. Participants are selected using snowball and criterion sampling methods. 8 participants were interviewed and the last two interviews were carried out to ensure saturation of information. The combined experience of participants is in excess of 100 years. Some organizations that the participants worked had already implemented CC, some yet to implement and some in advanced stages of implementation. This mix would give a holistic view of CC concept with respect to organizations in Saudi Arabia. Table 1 shows the profile of participants interviewed. All the responses are kept anonymous and the research work has followed all the relevant ethical guidelines throughout.

Table 1. Participants' profile

\begin{tabular}{|c|c|c|}
\hline Designation & $\begin{array}{c}\text { Number of } \\
\text { Participants }\end{array}$ & $\begin{array}{c}\text { Experience in DSS, } \\
\text { KM, and (or) CC }\end{array}$ \\
\hline $\begin{array}{c}\text { Head of } \\
\text { Operations }\end{array}$ & 1 & 20 years \\
\hline $\begin{array}{c}\text { Director of } \\
\text { Marketing }\end{array}$ & 1 & 25 years \\
\hline $\begin{array}{c}\text { Senior } \\
\text { Technology } \\
\text { Consultant }\end{array}$ & 1 & 20 years \\
\hline $\begin{array}{c}\text { Director of } \\
\text { Technology }\end{array}$ & 1 & 15 years \\
\hline $\begin{array}{c}\text { Senior Project } \\
\text { Manager }\end{array}$ & 1 & 14 years \\
\hline $\begin{array}{c}\text { Senior Team } \\
\text { Manager }\end{array}$ & 1 & 18 years \\
\hline $\begin{array}{c}\text { Senior Project } \\
\text { Consultant }\end{array}$ & 1 & 19 years \\
\hline $\begin{array}{c}\text { Head of } \\
\text { Customer } \\
\text { Services }\end{array}$ & 1 & 1 \\
\hline
\end{tabular}

\section{Results and Analysis}

Based on theoretical underpinnings, it has been established that CC has significant impact on DSS and KM. The relationship between CC, DSS and KM highlighted the challenges faced by DSS and KM. To validate these findings, the participants were interviewed on these topics. With the amount of experience of the participants in the various levels of management, they are considered to be experts in the area of this research topic. The results and analysis are divided into three categories: 1. Impact of CC on DSS, 2. Impact of CC on KM and 3. Impact of CC, DSS and KM on Saudi organizations.

\subsection{Impact of CC on DSS}

Most of the participants expressed that decision-making within the organisation has comea long way and considered DSS as a transformation in the decision-making process. They all generally agreed that DSS provided them the ability to deal with rapidly growing information. They all believed that the emergence of DSS is a major milestone that they have seen in their professional careers. Similar open-ended question was asked to what the participants feel about CC. After witnessing such huge transformations in the field of Information Technology (IT) and Information Systems (IS), three participants felt that CC will take the organisation to the next level. However, two participants felt that the major concern they have about $\mathrm{CC}$ is the data security. They were of the view that not organizations from all parts of the globe are yet ready to embrace technology such as CC. CC security has been a hot topic amongst academicians and researchers. Many scholars were also critical about the CC security. Figure 5 illustrates the various reasons given by participants about being slow in adopting new technologies.

However, we disagree with that view because no technology can emerge and become popular without any associated drawbacks or risks. We firmly believe that organizations should follow the recommended guidelines when implementing any new technology. We argue that with due diligence, organizations can make the most of the new technologies and stay ahead of its competitors. The common view of most of the participants was that CC is a good concept and is good for their respective organizations. Participants also expressed that CC is the best available option at the moment to handle such enormous amount of data flowing within and outside of 
the organisation. The organizations of four participants had already implemented CC, two participants said that they were in the final stages of implementation, and the two other participants said it is still in evaluation stage. It is evident that the companies are realising the importance of CC. This validates the theoretical underpinning that eventually companies will move to CC to handle the evergrowing data due to the emergence of social media and technological advancements as shown in Figure 6.

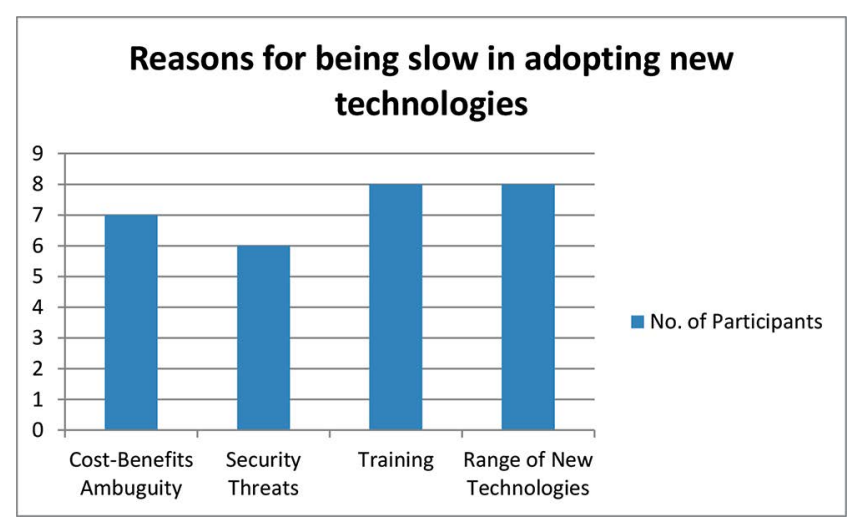

Figure 5. Reasons for being slow in adopting new technologies.

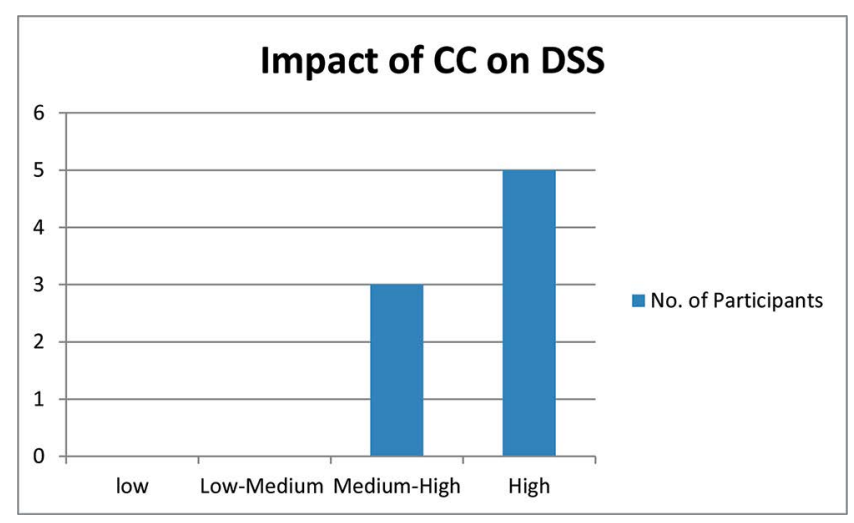

Figure 6. Impact of CC on DSS.

\subsection{Impact of CC on KM}

Most of the participants felt that KM is not being used to its potential. They also were of the view that knowledge should be used effectively and has to be integrated with DSS. Due to higher costs incurred in developing KM and streamlining the process, organizations are not keen on investing in KM. However, four participants suggested that CC has provided a major boost to KM framework. Most of the processes of KM are streamlined using CC and has increased its leverage in DSS. Similar concerns were highlighted in the earlier sections about KM. With the adoption of CC, it is clear that the organizations have started to reap benefits out of their KM systems that they were missing out earlier. Two participants were of the opinion that KM should not be a problem for smallsized organizations and tacit knowledge gets transmitted within the staff quickly. They further added that robust $\mathrm{KM}$ systems are necessary for small-scale companies if they have branches internationally. To sum up, mediumscale and large-scale organizations that are scattered across various sites need better KM systems due to the sheer amount of data transmission from various sources. It can be noticed that CC has a positive impact on both DSS and KM. However, at this juncture, it is critical to address the major issue concerning CC - security. As with any other technology, CC also faces various security threats such as malware injection, accountability check, wrapping attack, flooding attack and data stealing. Every organisation is required to evaluate the threats and take appropriate actions to mitigate these risks. $\mathrm{In}^{17}$ rightly warned that the security threats have the potential to damage the reputation of the organisation that can be fatal as shown in Figure 7.

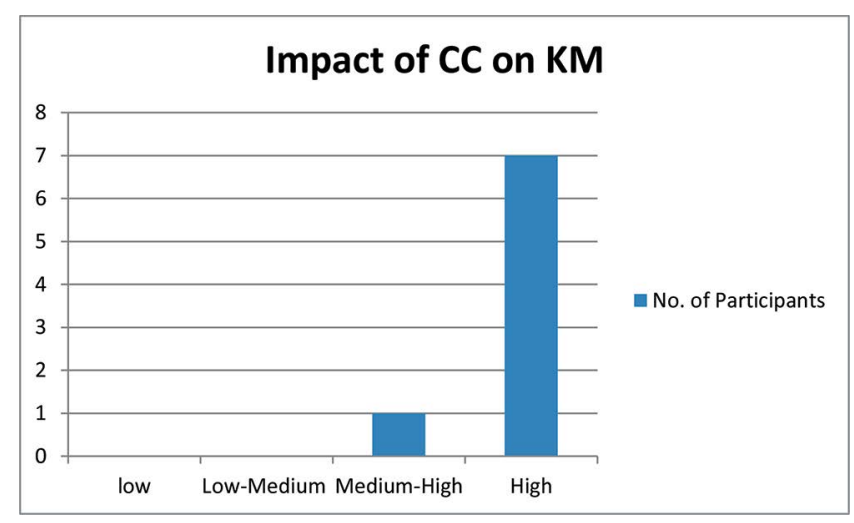

Figure 7. Impact of CC on KM.

\subsection{Impact of CC, DSS and KM on Saudi Organizations}

The next part of the interview was to specifically analyse the participants' views about the impact of CC, DSS and KM on Saudi organizations. Most of the participants felt that Saudi companies are trying to become big players in the international arena and are keen on adopting latest technologies to compete with existing big players around the world. Saudi companies are realising the need to stay up-to-date with the latest technologies in this highly competitive business environment. Due to globalisation, 
Saudi companies are getting exposure to the international business leaders and are willing to accept the global norms. One participant gave the example Saudi Telecom Company partnering with state-owned IT Company, ELM and the National Information Centre in transforming the government services. This clearly shows the growing confidence in CC amongst Saudi organizations and the government. One participant strongly expressed that in this globalised world, companies cannot risk ignoring the latest technologies and Saudi organizations are not making that mistake. Another participant said that CC has various services to offer irrespective of the sector and scale of the organisation. This is true because CC offers infrastructure, platform and software as a service that enables the companies to go for all or any of the services according to their requirement. The companies can also expand or opt for more services as and when they require. Based on the responses from the participants, it is evident that CC is becoming popular rapidly not just amongst Saudi companies but also with government agencies. This substantiates the findings of literature research that CC is a technology that has a positive impact on any type of organisation as shown in Figure 8.

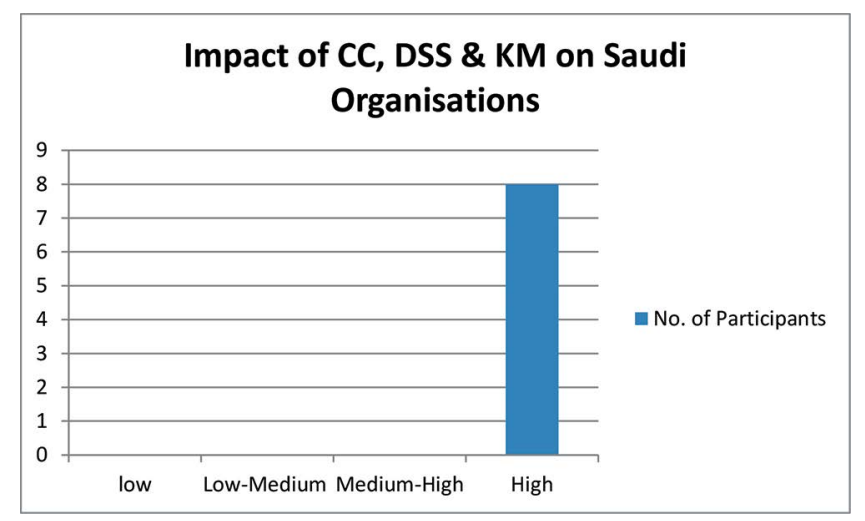

Figure 8. Impact of CC, DSS and KM on Saudi organizations.

\section{Recommendation and Conclusion}

This research explored the impact of CC on DSS in adopting KM in greater depth with respect to Saudi organizations. There was gap in research that integrated these technologies. Although this research was based on Saudi organizations, it will be useful for other researchers, companies and academicians. Based on the literature and qualitative research, we recommend the Saudi organizations to adopting CC in their DSS solely due to the cost effective benefits it has got to offer. CC has a lot to offer to all types of companies irrespective of the sector, scale and geographic location. We highlighted the limited usage of $\mathrm{KM}$ in companies resulting in losing leverage over its competitors. We strongly recommend making use of KM to its full potential with the implementation of CC. In this era of information, no company can afford to miss out on the opportunity that latest technologies like CC integrated with DSS and KM are offering. Based on the responses from the interview participants, it was evident that Saudi organizations are not that far behind in adopting CC for DSS. The amount of combined experience of participants who are experts in the field of technology, management and DSS reflects the true representation of ground reality in Saudi organizations. With this research, we have provided pointers for researchers to explore the impact of CC on other latest technologies such as Big Data and Artificial Intelligence. We generally believe that any technology cannot be free from security threats. With the advancement in technology, the security threats also get advanced and dangerous. However, we recommend all the organizations considering implementing new technologies should evaluate critically and take necessary precautionary measures to safeguard the company's and its customer's interests at all times.

\section{References}

1. Rittinghouse J, Ransome J. Cloud Computing: Implementation, management and security. CRC Press; 2009. p. 340.

2. Naldi M, Mastroeni L. Economic decision criteria for the migration to cloud storage. European Journal of Information Systems. 2014; 4:1-13.

3. Bhattacherjee A, Park SC. Why end-users move to the cloud: A migration-theoretic analysis. European Journal of Information Systems. 2014; 23(3):357-72. https://doi.org/10.1057/ejis.2013.1

4. Martens B, Teuteberg F. Decision-making in Cloud Computing environments: A cost and risk based approach. Information Systems Frontiers. 2012; 14(4):871-93. https://doi.org/10.1007/s10796-011-9317-x

5. Alharbi F, Atkins A, Stainer C. Understanding the determinants of Cloud Computing adoption in Saudi healthcare organizations. Complex and Intelligent Systems. 2016; 2:155-71. https://doi.org/10.1007/s40747-016-0021-9 
6. Khanghahi N, Ravanmehr R. Cloud Computing performance evaluation. Issues and Challenges. 2013; 3(5):29-41. https://doi.org/10.5121/ijccsa.2013.3503

7. Barnatt C. A brief guide to Cloud Computing: An essential introduction to the next revolution in computing; London: Robinson; 2010. p. 274.

8. Linthicum DS. Cloud Computing and SOA convergence in your enterprise: A step-by-step guide. Boston: Pearson Education; 2009. p. 264.

9. Shorfuzzaman M. Leveraging cloud based big data analytics in Knowledge Management for enhanced decision making in organizations. International Journal of Distributed and Parallel Systems. 2017; 8(1):1-13. https://doi.org/10.5121/ ijdps.2017.8101

10. VaqueroLM, Rodero-MerinoL,CaceresJ,LindnerM.Abreak in the clouds: Towards a cloud definition. ACM SIGCOMM Computer Communication Review. 2009; 39(1):50-5. https://doi.org/10.1145/1496091.1496100

11. Ristov S, Gusev M, Kostoska M. Cloud Computing security in business. International Journal of Network Security and its Applications. 2012; 4(2):75-93. https://doi.org/10.5121/ ijnsa.2012.4206
12. Jun L, Jun W. Cloud Computing based solution to Decision Making. Procedia Engineering. 2013; 15:1822-6. https://doi.org/10.1016/j.proeng.2011.08.339

13. Jula A, Sundararajan E, Othman Z. Cloud Computing service composition: A systematic literature review. Expert Systems with Applications. 2014; 41(8):3809-24. https://doi.org/10.1016/j.eswa.2013.12.017

14. Geczy P, Izumi N, Hasida K. Cloud sourcing: Managing cloud adoption. Global Journal of Business Research. 2012; 6(2):57-70.

15. Garg SK, Versteeg S, Buyya R. A framework for ranking of Cloud Computing services. Future Generation Computer Systems. 2013; 29(4):1012-23. https://doi.org/10.1016/j.future.2012.06.006

16. Kvale S. Inter views: Learning the craft of qualitative research interviewing. 3rd ed. Thousand Oaks: Sage Publications Linthicum; 2015.

17. Babcock C. Management strategies for the cloud revolution: How Cloud Computing is transforming business and why you can't afford to be left behind. New York: McGraw-Hill; 2010. p. 272. 